\title{
Surveying, shoring, strengthening: rebuilding medical morale from its foundations $\mathrm{s}^{\mathrm{N}} \mathrm{E}$
}

\author{
Authors: Arrash Yassaee, ${ }^{\mathrm{A}}$ Laura Cheetham, ${ }^{\mathrm{B}}$ Nick Manning-Cork, ${ }^{\mathrm{C}}$ Cassim Akhoon ${ }^{\mathrm{D}}$ and Arjun Gowda ${ }^{\mathrm{E}}$
}

Significant uncertainty surrounds the sustainability of healthcare services in which junior doctors work. It is essential that student and foundation doctors (SFDs) are actively engaged if workforce morale is rebuilt. This narrative review explores the evidence driving the individual work-streams of the Royal College of Physicians' newly formed Student and Foundation Doctor Network. Undergraduate and postgraduate training reform has coincided with concerning feedback from newly qualified doctors. System-level efforts to address this include a focus on extra-contractual matters, where small, sustainable changes could address training and work issues.

Fewer foundation year- 2 doctors are entering specialty training immediately after the foundation programme. Providing dedicated careers guidance and highlighting opportunities within traditional placements and other career paths can support doctors who undertake non-traditional career routes, including those who take time out of programme.

Disseminating these resources through an effective peerto-peer framework and a well-established mentoring scheme could be the most appropriate way to spread good practice.

KEYWORDS: Foundation, training, morale, workforce, trainee

\section{Introduction}

In April 2016, the NHS in England endured the first all-out 'junior doctor' strikes (encompassing both elective and emergency services) in its history. ${ }^{1}$ While contractual negotiations sparked the decision to ballot junior doctors, pre-existing and longstanding problems with junior doctor morale exacerbated the dispute. ${ }^{2}$ This distinction is particularly pertinent given that the terms and conditions of service for junior doctors in England

Authors: A specialty trainee year 1, paediatrics, Barts Health NHS Trust, London, UK; ${ }^{\mathrm{B}}$ core trainee year 2, Acute Care Common Stem (anaesthetics), Aneurin Bevan University Health Board, Newport, UK; ${ }^{C}$ foundation year-1 doctor, East Kent Hospitals University NHS Foundation Trust, Canterbury, Kent, UK; ${ }^{D}$ post-foundation programme doctor, Buckinghamshire Healthcare NHS Trust Amersham, Buckinghamshire, UK; ${ }^{\text {E }}$ post-foundation programme doctor, Nottingham University Hospitals NHS Trust Nottingham, Nottingham, UK is currently being reviewed by the British Medical Association and NHS Employers. ${ }^{3}$

Undergraduate medical education in the UK is between 4 to 6 years in length. Prior to specialty training, UK medical graduates also complete a 2-year Foundation Programme (FP) that rotates trainees through placements, delivering a broad curriculum predominantly through experiential learning. While this period cements trainees' continuing postgraduate development, these doctors represent the foundations of the profession's future.

With uncertainty around what their future professional working lives in the NHS will resemble, student and foundation doctors (SFDs) may feel justified in considering their commitment to a long-term career in healthcare. It is imperative that they are actively engaged and consulted if morale is to be rebuilt and whatever 'fractures the relationship between physicians and the state' is to be addressed.

Recently the Royal College of Physicians (RCP) established its Student and Foundation Doctor Network (SFDN). Representatives from across the UK meet regularly to discuss pressing issues affecting SFDs and how the RCP could address them. There are three work-streams: working lives, to survey the challenges within the foundations of junior doctor morale; careers development, to shore up these foundations; and local engagement and communication, to strengthen them for the future.

In this narrative review, we explore the evidence behind these goals. The review will explore recent reforms, successful solutions employed locally or in other sectors. We also illustrate the value SFDs can provide to policy by outlining a SFDN project.

\section{SFDs' working lives}

The past 15 years have seen major reforms to undergraduate and postgraduate training, including Modernising medical careers (MMC) which saw changes to specialty registrar training, first year of medical practice (pre-registration house officer) and the senior house officer system. ${ }^{4}$ The latter two changes resulted in the genesis of the FP (Table 1).

Critics argue that $\mathrm{MMC}$ has resulted in a more inflexible training structure which contributes to trainee attrition. Many also argue that it has resulted in the weakening of informal support networks through the loss of the firm and diminishing use of the mess. ${ }^{6}$ Solutions to address this have been varied and have included placing some postgraduate responsibilities on medical schools. ${ }^{7}$ Similarly, the Shape of Training review and a subsequent General Medical Council (GMC) report draw attention to the effect 
Table 1. Examples of challenges of previous pre-registration house officer and senior house officer grades with relevant changes included in the Foundation Programme to address these.

\section{Challenges of the PRHO/SHO system}

Short, stand-alone SHO placements with no overall co-ordination of training

No common competencies across placements

Lack of standardised end-of-placement assessment

Local, varying and often duplicated application process; requirement to apply for each $\mathrm{SHO}$ job every $4-6$ months

Service delivery and training imbalance with little accountability of training quality

Numbers of jobs based on local junior doctor need rather than workforce demands

Placements not allowing for specialty-specific competencies

Lack of formal career advice

Disparity between $\mathrm{PRHO}$ year reviewed by medical schools but trusts acting as PRHO employer

Limited placements variety with excessive focus on secondary care

Variable and often lacking supervision

\section{Change built into Foundation Programme}

Coordinated set of three to six placements designed to provide a balanced learning experience

Nationally agreed curriculum with minimum common competencies

Standardised end-of-placement reviews conducted through e-portfolio

Single centralised, national, standardised application process allocating 2 years of placements; occasional deaneries require selection of F2 placements based on F1 portfolio score

Aim to readjust this through mandatory, weekly teaching requirement with specific national feedback surveys on training quality

Numbers nationally agreed, based on predicted workforce requirements

Focus in Foundation Programme on broad-based, generalisable skills as per General Medical Council's duties of a doctor ${ }^{5}$

Requirement for formal careers advice and access to services

F1 sign off by postgraduate dean, assessment based by Foundation Programme director in trust.

Broader range of available placements with recent commitment to ensure more foundation doctors undertake a community placement

Requirement to have allocated clinical and educational supervisor; national surveys assess level of day-to-day supervision

$\mathrm{F} 1=$ foundation year $1 ; \mathrm{F} 2=$ foundation year $2 ; \mathrm{PRHO}=$ pre-registration house officer; $\mathrm{SHO}=$ senior house officer

of recent reforms on trainee experience, training quality and workforce retention. ${ }^{8-10}$

Undergraduate curricula and its delivery have also been progressively modified in line with sequential GMC guidance from 'Tomorrow's doctors' to Promoting excellence: standards for medical education and training. ${ }^{11,12}$ Most notably, practical skills training has shifted from a 'see one, do one' format to initial simulation and/or clinical skills laboratory training followed by competency-evidenced skill practice. This, in part, reflects changing sector-wide approaches to safety. ${ }^{13}$

However, these reforms have coincided with concerning feedback. The GMC surveys cite that reported preparedness for practice of new doctors rose from $26 \%$ in 1999 to $58 \%$ in 2005 . After the introduction of the FP, improvements stagnated, with only $49 \%$ of 2009 graduates feeling that medical school had adequately prepared them for practice. A more in-depth study found further evidence of poor self-reported preparedness. Graduates, in addition to supervisors, reported that up to $28.3 \%$ of foundation doctors (FDs) failed to cope with the transition from medical school. ${ }^{14}$ Trainers also have concerns regarding graduates' competence in several areas, including prescribing, interpersonal skills, and diagnosis and management of acutely unwell patients. ${ }^{15}$ The newly introduced burnout questions within the GMC's national training survey 2018 reveal that FDs report the highest work intensity and feelings of burnout along with feeling that they were on a 'training treadmill' of continuous 'tick box' assessments. ${ }^{16}$
This highlights the difficulty of the sharp transition from medical student to practising physician with frequent rota gaps and often scarce senior availability. ${ }^{17}$ These findings also demonstrate that training reforms often fail to take a holistic view of the pressures experienced by FDs, with recent reports identifying that these are linked to worsening workforce retention., ${ }^{9,10}$ Curricula and programme design would be enriched by a greater awareness of these pressures, some of which are outlined in Table 2.

Recent system-level efforts to address these challenges include the 2016 terms and conditions of service in England and the ongoing FP review. ${ }^{42}$ Key stipulations, including improved limits on safe working hours, a system to report deviations from planned rostering arrangements as well as the creation of the 'guardian of safe working hours' role, are designed to address issues surrounding overtime and missed breaks.

Provision of hot and cold sustenance and facilitating rest breaks for doctors on long shifts are examples of the eight high-impact actions published by NHS Improvement, recommended as enhancements to the working environments of junior doctors in line with the widespread recognition of the benefits of such provisions in other sectors. ${ }^{43}$

Recognising these challenges and the efforts to address them, the SFDN established a working lives work-stream focusing on extra-contractual matters, where small, sustainable changes could address training and work issues. The work-streams' activities have all been mapped to documented issues that SFDs face, solutions 
Table 2. Current challenges to the wellbeing and morale of student and foundation doctors

Issue

\section{Brief examples}

Poor mental

health

support

Financial stress

Physical stress

Limited spare time

Frequent location changes activities. $^{3,18,19}$ progression. $^{19,24}$ time. $^{33}$ stressors. ${ }^{27,33}$
Variable access to support systems for SFDs. Fears of implications for progression of career if distress is acknowledged. ${ }^{6}$

Limited time outside work to engage in stress-reducing

Negative stigma attached to mental health difficulties. ${ }^{6,20}$

SFDs experience, like other NHS staff, higher levels of stress and ill health compared to other professions. ${ }^{21}$ Stress and associated mental health difficulties result in impaired concentration. ${ }^{22,23}$

Increased tuition fees from $£ 1,000$ per year to $£ 9,000$ per year, required self-funding of transport to placements and of professional development training required for career

On average, $\mathrm{F} 2 \mathrm{~s}$ spend $£ 1,854$ ( $5 \%$ of their basic annual pre-tax salary) and at most $£ 3,500$ on career development courses and examinations. ${ }^{25}$ Higher relative cost of living, below inflation pay rises and loss of employment packages such as free on-site accommodation and subsidised catering and rising cost of mandatory training courses. ${ }^{24}$

Ignoring basic needs for food, drink, rest and toilet breaks, to fulfi service pressures. $^{18,26,27}$

Unwritten rules such as not sleeping on night shifts, irregular hours of work. ${ }^{28-31}$ Twenty-one per cent of the 2018 national training survey respondents state that working patterns mean that they feel regularly short of sleep and in 2017 that limited access to food onsite affected trainee morale. ${ }^{16,32}$

Trainees have also stated work patterns led to poor quality learning within workplace and voluntary self-study in personal

Stress reduces physical endurance, immunity and is linked to increased risk for chronic diseases. ${ }^{34-37}$

Undergraduate training requires extensive self-directed study, with more online accountability via monitoring systems embedded into e-learning platforms.

Both the 2017 and 2018 national training surveys found $>50 \%$ of junior doctors work overtime due to service delivery demands and reduced staffing numbers. ${ }^{16,32}$ Portfolio and specialty application preparation requiring investment of time outside of work. ${ }^{33}$ FDs use an average of 8.1 days of annual leave for voluntary, self-funded educational reasons while $85 \%$ of $\mathrm{F} 1$ s and $100 \% \mathrm{~F} 2$ s engaged in voluntary e-learning outside of work to supplement work-based training. ${ }^{25}$ Reduces resilience and time available to consistently recharge mental and physical batteries and to address personal

For both medical students and FDs - requiring variable, often lengthy commutes to placement sites compounded by removal of on-site accommodation. ${ }^{38}$ Location changes often not available well in advance, affecting planning of personal circumstances and life events. ${ }^{33}$ Location changes removing SFDs from support network.

\section{SFDN response}

Showcasing local and national examples of innovative initiatives that have improved SFDs' wellbeing.

Highlight the feasibility of wellbeing initiatives and the tangible benefits for SFDs and, in turn, medical schools, trusts and health boards, and empower SFDs to become involved in finding practical solutions.

Presenting a narrative review of student support systems at the Royal Society of Medicine's Student Policy Initiative.

Guides are being developed to give members direct experiential advice from SFDs.

'How to...' and experience guides promoting the importance of holistic wellbeing, practical peerwritten guides on how to navigate situations that can negatively impact on physical health and promote openness, acceptance and recognition of the fact that SFDs will encounter physical stressors.

Providing guidance on aspects key to maximising wellbeing such as time management; how others have found a balance and a sense of peace I ways to decompress outside work; strategies to 'fill' the 'resilience tank'

Providing peer-authored resources about how to maximise opportunities and overcome challenges associated with location changes. Showcasing examples of where undergraduate and postgraduate centres have developed schemes designed to reduce stress of location changes. 
Table 2. (Continued)

Issue

Transition

from medical

student to FD

\section{Brief examples}

Translating theoretical or observed knowledge into practice, so feeling 'unprepared for practice'. ${ }^{14,39}$

Imbalance between service provision and training

Qualification and training programmes

Burden of career development placed on trainee

Poor morale
High work intensity, large volume of administrative tasks, rota gaps and reduced opportunities for on-the-job learning. ${ }^{33}$

Frequent changes in shift pattern affect protected teaching time and time available for study outside of working hours. Work intensity and shift patterns reduce motivation to study. ${ }^{38}$

In the 2016 junior doctor review, junior doctors stated that there was little interest in their own personal development, often due to frequent placement changes. ${ }^{40}$

Forty-one per cent of the 2018 national training survey respondents stated workload was heavy or very heavy. Almost $50 \%$ of trainees reporting having to work over rostered hours at least once a week. Thirty per cent of trainers felt unable to use the time allocated to them for education for this purpose and $28 \%$ stated they did not have enough time for education built into job plan. $32.3 \%$ of trainees and $28 \%$ of trainers who responded stated educational/ training opportunities were being lost due to rota gaps. ${ }^{16}$

Frequent assessments for students, FDs having to spend many off-duty hours on portfolio to complete work based assessments, mandatory audits and evidence competencies. ${ }^{19}$

Forty-four per cent of the 2017 national training survey respondents stated that mandatory training was subtracted from study leave allowance. ${ }^{32}$

Mismatch between specialty person specifications and FP requirements result in FDs undertaking required professional development in personal time. ${ }^{17}$

Ninety per cent of FDs feel the need to develop their curriculum vitae further via voluntary educational activities. ${ }^{23}$

Prevailing culture prizing perfectionism, studying and working in an overburdened system. ${ }^{41}$

More than $50 \%$ of F2s in 2017 reporting 'burnout' as reason for taking a career break. ${ }^{10}$ In 2018 , the highest numbers of trainees reporting burnout were $\mathrm{F} 2 \mathrm{~s}$ at the end of their FP training. ${ }^{16}$

Difficulties in FDs' ability to arrange annual leave when needed, or of sufficient continuous length to provide meaningful rest. ${ }^{10}$

Isolation - placement location changes move SFDs away from support network, demonstrates lack of control trainees have over lives. ${ }^{33}$

Lack of receptiveness and flexibility of systems such as work/ placement rotas. Rigid training structures mean SFDs face stressful challenges and guilt when juggling caring/family responsibilities. ${ }^{38}$

\section{SFDN response}

Providing peer-written pieces on key practical and emotional challenges to help bridge the gap between student and FD. Engender a sense of a virtual community, reducing isolation. Pieces that encourage SFDs to articulate their challenges and find constructive solutions. Representing the position of SFDs such as in the recent Royal College of Physicians' junior doctor prescribing report

Providing advice from SFDs about managing time and projects. Providing personal experiences of SFDs to engender a sense of a community and camaraderie, and tangible pieces of advice and support.

Sharing best practice of flexibly delivered postgraduate teaching that combines training requirements with service provision needs

Advice on managing multiple commitments, personal stories about facing and surviving stressful training/assessment situations.

Campaign challenging perfectionist culture by highlighting 'failure' as strength.

Promoting professional development by co-hosting poster presentation. Providing 'How to...' guides and experiences written by SFDs about topics such as how to manage one's time, meet career development needs while leading fulfilling lives, maintaining good health.

Through providing resources that give constructive solutions and also challenge isolationism, reject perfectionism and recognise burnout, sharing peer and near-peer experiences and advice to provide a sense of community and break down isolationism. SFDN 'strength through failure' golden thread challenges and erodes the concept of perfectionism and negative stigma associated with failure.

By providing a conduit for SFDs to talk about these issues and provide their valuable experiences and advice, improves engagement and perception of value of SFD by peers and the Royal College of Physicians.

By being able to engage, shape and contribute to the work of the SFDN, this will empower grassroots SFDs and provide a constructive conduit for tackling negative, and highlighting positive, aspects of their working lives

$\mathrm{FD}=$ foundation doctor; $\mathrm{FP}$ = Foundation Programme; F1 = foundation year-1 doctor; F2 = foundation year-2 doctor; SFDN = Student and Foundation Doctor Network; SFDs = student and foundation doctors 
for each of which are supported by evidence and/or membership feedback. These are outlined in Table 2.

\section{SFD career development}

Only $37.7 \%$ of foundation year-2 doctors who completed their FP in 2018 immediately commenced specialty training; down from $66 \%$ in $2012 .{ }^{44}$ Reflecting this, unfilled vacancies increased by $31 \%$ since $2016 .{ }^{45}$ This trend results in increasing NHS agency staff spend and risks providers' ability to provide sustainable, good-quality care.

Discussions with FDs have revealed that the likely reasons to delay formal training include gaining experience in different specialties and overseas healthcare systems, and acquiring qualifications not possible in structured training programmes. Interestingly, FDs also placed importance on developing 'soft' skills such as time management and networking, as well as being able to pursue elements of a portfolio career which they felt enabled to do outside training. ${ }^{10}$

FDs are typically expected to apply for specialty training programmes shortly after beginning their second year of postgraduate training, often not experiencing their specialty of interest due to limited control over rotation selections. In order to demonstrate commitment to a highly competitive specialty, trainees must plan their application and tailor their curriculum vitae (CV) years in advance. This can result in significant time and financial pressures at a career stage where financial resources are already limited.

Contributing to this issue is the fear of significant difficulties induced by choosing the 'wrong' specialty, and eventually needing to switch training programme via a system that does not comprehensively recognise transferrable skills. ${ }^{9}$ This is heightened by an increasing rigidity in medical career paths, new contractual terms in England decreasing the potential to receive payprotection, and the disadvantage that may face candidates with a $\mathrm{CV}$ focused on a different specialty. This is also an issue which the GMC is attempting to resolve., ${ }^{9,46}$

To address these issues, the SFDN established a careers development stream to compile resources to facilitate informed career decisions for SFDs.

This includes 'How to...' guides to plan electives - an undergraduate placement, often abroad, with the aim of giving students a different experience of medical practice from their medical school; and 'taster weeks' - short postgraduate placements offering insight into specialties outside of an FD's allocated rotations. Further guides will focus on topics often not formally taught at medical school, such as conference presentations, peer-reviewed research and undertaking quality improvement projects. These resources are aimed to help SFDs to realise their professional and personal goals while contributing to a system-wide effort to tackle unfilled vacancies.

\section{Year-out-of-training: more than a 'gap year'}

A major contributor to NHS service provision, the insight that FDs provide goes beyond morale and career issues. One of the SFDN's focuses is to address a growing workforce challenge - FDs taking time out of training (TOT), often informally named an 'F3 year'.

The number of FDs taking TOT increases year upon year. At present, the majority of these FDs eventually return to take up specialty training posts in the UK. ${ }^{47,48}$ There is little research-based evidence to explain the underlying reasons for this, but theorised reasons are outlined in Fig 1. 8,10,47,49 The richest source of data thus far highlights three broad groups of

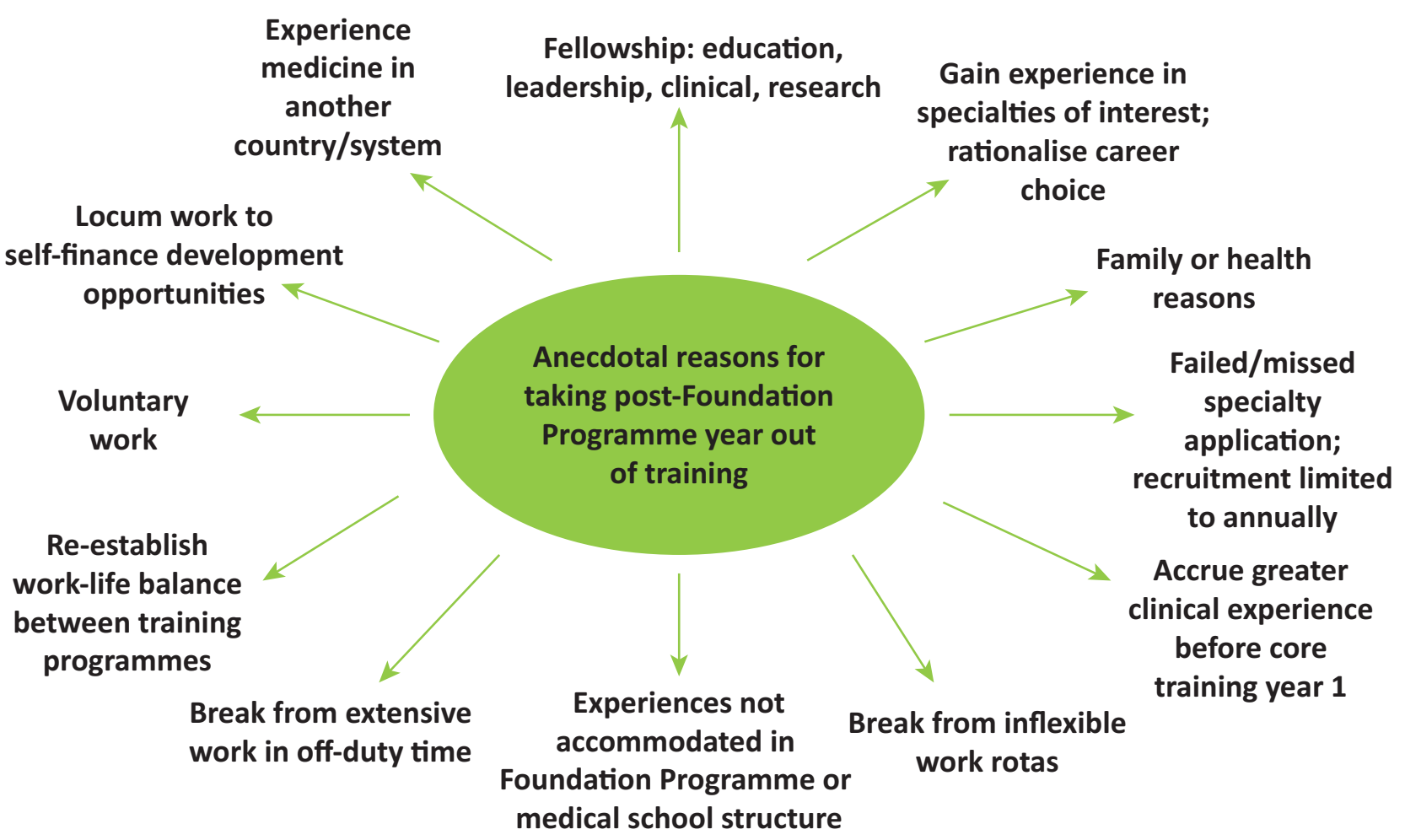

Fig 1. Proposed underlying reasons for foundation doctors to take a year out of training. 
motivating factors for deciding on a TOT/F3 year; health and wellbeing, specialty and future career, and training environment dissatisfaction. ${ }^{10}$

Junior doctors highlighted lack of autonomy, inability to explore future specialty careers, a need to develop nontechnical skills and qualifications they felt unable to do in a formal training programme as additional driving forces for taking TOT. ${ }^{50}$

A recent Scotland-wide survey of FDs examined factors that affected the likelihood of FDs pursuing an F3 year. This study identified five factors that influenced the decision to continue to further formal training:

geographical location

> supportive working and learning environment

$>$ good working conditions

opportunities for professional development

familiarity with specialty.

Potential earnings did not affect the decision to continue formal training; however, quality of professional development opportunities was a significant factor. FDs who opted for an F3 year placed greater weight on supportive culture and good working conditions than those who applied for further training. ${ }^{51}$

In the interests of workforce planning, it is imperative to examine how the NHS can utilise TOT doctors and facilitate their return to training as well as how to enhance the development of these doctors. ${ }^{52}$

As outlined in Fig 1, many motivations for TOT are pastoral. Enabling these doctors to return to training with enhanced skills and broader experience upskills the workforce and reduces future deficits in middle grade and senior rotas while preventing additional delays in training progression.

More than half of post-FP doctors chose to undertake TOT. Over $90 \%$ return to UK training within 3 years. ${ }^{50,52}$ More guidance and advice to enhance the developmental value of this time is in the interests of both FDs and the NHS. ${ }^{10}$

Through signposting and tailored guidance, the SFDN can support easier access to personal and professional development opportunities which are not possible while in full-time training such as research or education qualifications and fellowships, leadership roles or developing new clinical competencies (eg ECHO qualifications). This would allow FDs to pursue professionally enriching experiences without detriment.

In acknowledgement of this, the SFDN is working to address some of these key issues. Actions and outputs include:

> case studies of previous F3 experiences to reflect the diverse possibilities available, particularly valuable to doctors who undertake TOT for pastoral reasons

> guidance for how an F3 year can enhance a doctor's portfolio and illustrate how these experiences benefit the health service on return to training

$>$ advice on planning an F3 year that incorporates personal and professional development, including the appraisal process. ${ }^{10}$

The SFDN will highlight the unmet needs of these doctors, open discussions about the professional development of doctors who undertake TOT and provide informative, accessible resources. This project should make a tangible and directed difference to those FDs aspiring to improve their experience and development through an $\mathrm{F} 3$ year.

\section{Local engagement and communication with SFDs}

There is growing evidence of how different teaching methods are more appropriate for different learning requirements. ${ }^{53}$ To help improve the influence of the SFDN's work and engage SFDs with the RCP's services, activities and work, the local engagement and communications work-stream will be drawing on this evidence pool to deliver its content to members.

Outside the clinical settings, most notably through Schwartz rounds and action learning sets, sharing of ideas and learning with each other in a safe environment helps address the non-clinical demands of working and studying in the NHS, such as emotional and social stress. ${ }^{54}$ As discussed earlier, these elements of medical practice are often overlooked despite being a significant contribution to poor morale and burn-out.

Previously, SFDs relied on word of mouth within a close-knit medical firm for extra-contractual and non-clinical information. With the loss of firm-based working, junior colleagues are now more likely to seek advice from unverified online sources. Even with advances in information sharing, reputable, evidence-based answers to key questions are challenging to locate. Historically, the royal colleges have provided professional guidance and the SFDN will offer a natural extension of that role by signposting SFDs to credible relevant resources. ${ }^{55}$

Original content is written by current SFDs using a peer-to-peer framework, a model with a burgeoning amount of evidence, particularly for topics within the 'unwritten curriculum'. ${ }^{56}$ Nearpeer and peer-to-peer training supports both engagement and promotion of effective learning. ${ }^{57-59}$ Peers and near-peers have had recent experience of the challenging situations and aspects of training so can offer realistic advice, without the conflict of being involved in the SFDs' assessments.

As these services are joined by others provided by the SFDN, the value of a dedicated local engagement and communications workstream will continue to increase. Integrating this from the outset of the network's activities ensures a clear strategy on both the production and dissemination of resources for SFDN members.

\section{Conclusion}

SFDs are faced with an increasing number of challenges across domains including training, career progression and morale. Many of these are based on long-standing problems although some have been exacerbated by recent trends within healthcare and wider society.

As the group that will face the greatest impact from future training and healthcare reforms, it is important that SFDs are involved as partners in future change and that their unique insights are integrated as part of holistic solutions. Furthermore, as a major component of current and future NHS service provision, it is imperative that measures to improve their engagement, morale and retention within the NHS are considered seriously and given sufficient resources.

Multiple bodies already have dedicated groups for addressing SFD issues. However, recent junior doctor industrial action has shown that the royal colleges can play a different role in brokering constructive solutions to workforce problems. As part of the RCP, the SFDN with dedicated work-streams for working lives, career development and local engagement and communication can offer positive, informed solutions. 


\section{References}

1 Goddard A. Lessons to be learned from the UK junior doctors' strike. JAMA 2016;316:1445-6.

2 General Medical Council. State of medical education and practice in the UK. London: GMC, 2018.

3 NHS Employers. 2018 contract review of the junior doctor terms and conditions of service. NHS, 2018. www.nhsemployers.org/ news/2018/06/2018-contract-review-of-the-junior-doctorterms-and-conditions-of-service.

4 House of Commons Health Committee. Modernising medical careers: Third report of session 2007-08: Volume I. London: The Stationery Office, 2008.

5 General Medical Council. The duties of a doctor registered with the General Medical Council. London: GMC, 2019.

6 Cohen D, Winstanley S, Palmer P et al. Factors that impact on medical student wellbeing - perspectives of risks. Cardiff: Cardiff University, 2013.

7 Tooke J. Aspiring to excellence: final report of the independent enquiry into modernising medical careers. London: Aldridge Press, 2008.

8 Greenaway D, Shape of Training. Securing the future of excellent patient care. Final report. Shape of Training, 2013.

9 General Medical Council. Adapting for the future: a plan for improving the flexibility of UK postgraduate medical training. London: GMC, 2017.

10 General Medical Council. Training pathways 2: why do doctors take breaks from their training? London: GMC, 2018.

11 General Medical Council. Outcomes for graduates: 2018. London: GMC, 2018.

12 General Medical Council. Promoting excellence: standards for medical education and training. London: GMC, 2015.

13 Rodriguez-Paz JM, Kennedy M, Salas E et al. Beyond 'see one, do one, teach one': toward a different training paradigm. BMJ Qual Saf 2009;18:63-8.

14 General Medical Council. Be prepared: are new doctors safe to practise? London: GMC, 2017.

15 van Hamel C, Jenner LE. Prepared for practice? A national survey of UK foundation doctors and their supervisors. Med Teach 2015;37:181-8.

16 General Medical Council. Training environments 2018: Key findings from the national training surveys. London: GMC, 2018.

17 Morrow G, Burford B, Carter M, Illing J. The impact of the working time regulations on medical education and training: final report on primary research. Durham: Durham University, 2012.

18 Parish E. A priority for patient care is to start caring about ourselves and one another. BM], 2017. http://blogs.bmj.com/ bmj/2017/05/31/a-priority-for-patient-care-is-to-start-caring-aboutourselves-and-one-another [Accessed 23 November 2017].

19 Butler J, Greszczuk C, Yarlott L, Stevens R. The vital signs for medical students: supporting you through medical school. London: Royal Medical Benevolent Fund, 2017.

20 Grant A, Rix A, Mattick K, Jones D, Winter P. Identifying good practice among medical schools in the support of students with mental health concerns. London: GMC, 2013.

21 Royal College of Physicians. Working and wellbeing in the NHS: why staff health matters to patient care. London: RCP, 2015.

22 Abdulghani HM, Al-harbi MM, Irshad M. Stress and its association with working efficiency of junior doctors during three postgraduate residency training programs. Neuropsychiatr Dis Treat 2015;11:3023-9.

23 Scott SB, Graham-Engeland JE, Engeland CG et al. The effects of stress on cognitive aging, physiology and emotion (escape) project. BMC Psychiatry 2015;15:146.

24 Gajendragadkar P, Khoyratty S. Junior doctors' accommodation more than just the money. BMJ 2009;339:b3570.

25 Keogh M, Findlay ], Sithamparanathan S, Matheson D. Education in the Foundation Programme: what doctors are doing and why. $\mathrm{Br}]$ Med Pract 2010;3:306.
26 Newby G, Bichard H, Campbell N, Odiyoor M, Pinder C. Reclaiming the lost art of lunch. BM], 2017. http://blogs.bmj.com/ bmj/2017/05/02/gavin-newby-reclaiming-the-lost-art-of-lunch.

27 Tweedie J, Goh Y, Yarlott L, Choudry M, RCP's Trainees Committee. Being a junior doctor: Experiences from the front line of the NHS. London: RCP, 2016.

28 Afonso P, Fonseca M, Pires JF. Impact of working hours on sleep and mental health. Occup Med 2017;67:377-82.

29 Bunn S, Tankelevitch L. POSTNOTE 586: Shift work, sleep and health. London: Parliamentary Office of Science \& Technology, 2018.

30 Gulland A. Is sleeping on nightshifts just a dream? BMJ 2017;356:j1006.

31 Arendt J. Shift work: coping with the biological clock. Occup Med 2010;60:10-20.

32 General Medical Council. 2017 national training surveys summary report: initial results on doctors' training and progression. London: GMC, 2017.

33 Rich A, Viney R, Needleman S, Griffin A, Woolf K. 'You can't be a person and a doctor': the work-life balance of doctors in traininga qualitative study. BMJ Open 2016;6:e13897.

34 Davis S, Mirick DK, Stevens RG. Night shift work, light at night, and risk of breast cancer. J Natl Cancer Inst 2001;93:1557-62.

35 Pan A, Schernhammer ES, Sun Q, Hu FB. Rotating night shift work and risk of type 2 diabetes: two prospective cohort studies in women. PLoS Med 2011;8:e1001141.

36 Priyadarshini S, Aich P. Effects of psychological stress on innate immunity and metabolism in humans: a systematic analysis. PLoS ONE 2012;7:e43232.

37 Schernhammer ES, Laden F, Speizer FE et al. Night-shift work and risk of colorectal cancer in the nurses' health study. J Nat/ Cancer Inst 2003;95:825-8.

38 Brown $M$, Tucker $P$, Rapport $F$ et al. The impact of shift patterns on junior doctors' perceptions of fatigue, training, work/life balance and the role of social support. BMJ Qual Saf 2010;19:e36

39 Monrouxe LV, Grundy L, Mann M et al. How prepared are UK medical graduates for practice? A rapid review of the literature 2009-2014. BMJ Open 2017:7:e013656.

40 Health Education England. Health Education England listening exercise: junior doctor morale. HEE, 2016.

41 Enns M, Laden F, Cox B, Sareen J, Freeman P. Adaptive and maladaptive perfectionism in medical students: a longitudinal investigation. Med Educ 2001;35:1034-42.

42 NHS Employers. TCS for doctors and dentists in training (England) 2016. NHS, 2016.

43 World Health Organization, Burton J. Healthy workplace framework and model: Background and supporting literature and practices. Geneva: WHO, 2010.

44 General Medical Council. How do doctors progress through key milestones during training? London: GMC, 2016.

45 Oxtoby K. Switching specialty. BMJ 2009;338:b1768.

46 Royal College of Physicians. Doctors as leaders accreditation. London: RCP, 2015.

47 Goldacre M, Davidson J, Lambert T. Retention in the British National Health Service of medical graduates trained in Britain. BMJ 2009;338:b1977.

48 Rimmer A. Half of foundation trainees now choose not to progress straight to specialty training. BMJ 2017;356:j592.

49 General Medical Council. Training pathways: analysis of the transition from the foundation programme to the next stage of training. London: GMC, 2017.

50 Scanlan GM, Cleland J, Johnston P et al. What factors are critical to attracting NHS foundation doctors into specialty or core training? A discrete choice experiment. BMJ Open 2018;8:e019911.

51 UK Foundation Programme Office. F2 career destinations report 2018. UK Foundation Programme Office, 2018. 
52 Goldacre M, Davidson ], Lambert T. The junior doctor exodus. BM] 2010;341:c5643.

53 Samarakoon L, Fernando T, Rodrigo C, Rajapakse S. Learning styles and approaches to learning among medical undergraduates and postgraduates. BMC Med Educ 2013;13:42.

54 Lown B, Manning C. The Schwartz Center Rounds: evaluation of an interdisciplinary approach to enhancing patient-centered communication, teamwork, and provider support. Acad Med 2010;85:1073-81.

55 Royal College of Physicians. Guidelines \& Policy. www.rcplondon.ac.uk/guidelines-policy.

56 Basnak J, Ortynski ], Chow M, Nzekwu E. A digital peer-to-peer learning platform for clinical skills development. Can Med Educ J 2017:8:e59-66.

57 Gibson KR, Qureshi ZU, Ross MT, Maxwell SR. Junior doctor-led 'near-peer' prescribing education for medical students. $\mathrm{Br}$ ] Clin Pharmacol 2014:77:122-9.
58 Haslam P, Yau C, Rutter C. Junior doctor-led practical prescribing course. Clin Teach 2014;11:29-32.

59 Sukcharoen K, Everson M, van Hamel C. A novel approach to junior doctor induction: A near-peer based curriculum developed and delivered by outgoing foundation year doctors. BMJ Open Quality 2014:3:u203556.w1603.

Address for correspondence: Dr Laura Cheetham, core trainee year 2, acute care common stem (anaesthetics) trainee, Aneurin Bevan University Health Board, Lodge Road, Caerleon, Newport NP18 3XQ, UK.

Email: lauracheetham@nhs.net

\section{Royal College} of Physicians

\section{Looking for jobs in medicine?} Find your next hospital job

Find out more and subscribe to the monthly Medicine Jobs bulletin at www.rcplondon.ac.uk/jobsboard 